\title{
CrimRxiv
}

\section{Discounting Females,}

Denying Sex, and

Disregarding Dangers from

Self-ID: A Reply to Mezey,

Upadhyay, and Sherrick

\section{Callie Burt ${ }^{1}$}

${ }^{1}$ Georgia State University

Published on: May 13, 2021

DOI: $10.21428 / \mathrm{cb} 6 a b 371.8298 \mathrm{e} 7 \mathrm{~d} 8$

License: Creative Commons Attribution 4.0 International License (CC-BY 4.0). 


\section{ABSTRACT}

In this reply, I address responses to my article "Scrutinizing the Equality Act", where I argued that we should provide protections to LGBT+ individuals without prioritizing gender self-identification over biological sex. The bill would eliminate sex-based rights and the protected nature of women's provisions as a result of in-the-moment self-ID. Here, I reiterate my key points to correct misunderstandings and to refocus on the complex, contested issues raised in my article about balancing competing rights. I conclude by encouraging feminists to engage with the Equality Act's deficiencies.

Keywords: Equality Act, feminism, sex and gender, LGBTQ, women's rights

The explicit aim of my article was to stimulate a discussion around the U.S. Equality Act (EA) that considers sex and female people as well as gender and transgender people. This requires recognition of the distinction between sex and gender, competing sex-based and gender-identity-based rights, and the problems with self-ID. The prevailing disregard for the EA's effect on females, I argued, follows from this topic being deemed too harmful to trans people to discuss. Accusations of transphobia are weaponized to discredit those who not only raise reasonable concerns about the replacement of sex with gender identity under the law, but also, in some cases, simply recognize the material reality of sex and the distinction between sex and gender.

This censoring of discussion and consequent lack of viewpoint diversity is concerning. The hazards of unchallenged groupthink are well established. Because of the narrow, and no doubt well-intended, focus on the struggles of transgender people, scholarship and policies have neglected to consider females. The result is an EA that would extend rights to transgender people by eliminating the sex-based rights of female people and, still worse, undermine the safety of both via self-ID. All perspectives have blind spotsit's impossible to focus on everything at once-and this is precisely why viewpoint heterodoxy and dissent are essential in the academy.

Against this backdrop, I appreciate the responses to my article and the opportunity to correct the record, clarify, concur, and dissent. An enforced limitation on space requires selectivity, but I have tried to respond to their major critiques. First, I briefly summarize the substance of my arguments before addressing their objections. 


\section{Precis of My Arguments}

Explicitly supporting the bill's aims-protecting LGBT+ people from discrimination-I argued that the EA was deficient in form. The bill extends LGBT protections by redefining 'sex' in civil rights law to 'include sexual orientation and gender identity' and by prioritizing gender identity over sex. My primary objection to the bill is its prioritization of in-the-moment gender-self-ID 'regardless of sex' for access to 'sexseparated' provisions. Under the EA, predatory males can at any time gain legal access to women's provisions merely by saying 'I identify as a woman'. The EA thus undermines the protected nature of women's provisions. For a provision to be a protected one, access has to be restricted. If any male can identify into women's provisions on a say-so, it is no longer a protected space.

This sweeping legislation was done in the absence of any obvious consideration, such as policy impact evaluation, for females. I argued the continued failure to consider the consequences of gender self-ID is irresponsible. I proposed that we protect LGBT+ people by creating two new protected categories in civil rights law: sexual orientation and gender status. When sex-based provisions are deemed legitimate-for privacy, safety, fairness, well-being (e.g., in prisons, shelters, showers, sports)-we allow sexbased distinctions and provide protected gender-neutral (or gendered) spaces.

\section{Disregard for Females and the Dangers of Self-ID}

Professor Mezey (2021) disagrees with what she perceives to be my premise, namely that the "2019 Equality Act disadvantages women by blurring the distinction between sex and gender identity" (p.1). This is not quite right. The EA does not 'blur'; it eliminates the legal distinction between sex and gender. Membership in the female sex class would be legally defined on the basis of a self-utterance. $\underline{1}$ Moreover, my argument was not that the EA's elimination of sex-based provisions would 'disadvantage' females. Rather, as I discussed (see Burt 2020, pp.369-71), females are disadvantaged due to sociohistorical laws and customs limiting female participation in society as well as physiological differences, such as strength, size, and the labor of reproduction, all of which position females dissimilarly to males in some contexts (e.g., safety, self-defense, sport).

Most women recognize that they are vulnerable to males from an early age; we learn to live with the reality of our vulnerability to male violence, especially male sexual violence, by being proactive: don't go out at night alone, don't accept drinks from male strangers (and watch your drink), do carry a rape whistle. Sex-separated spaces allow 
females to be largely free of the threat of men's violence and sexual objectification. Of course, some men will break rules about sex-separation; crucially, however, we can object to their presence and remove them if they do so. By eliminating females' right to exclude predatory males based on sex, the EA will eliminate these remedies to female disadvantages, which promote safety and equal social participation.

\section{Disregarding Self-ID, Ignoring Male Violence, and Inverting the Burden of Proof}

Mezey claims that I "did not make a sufficient case that the Act's interpretation [read: redefinition] of sex would harm women." Acknowledging that I did not suggest transwomen pose any particular danger, Mezey perceives my argument to be that 'the Act would allow, even encourage cisgender men to present as women and invade women's sex-segregated spaces to prey on them,' but '[t]here are ample data' from 'jurisdictions with anti-discrimination laws that cast doubt on these assertions.' Further, she suggests, my raising these concerns 'perhaps unwittingly...perpetuate[s] discrimination against the transgender community'. I address each point in turn.

First, Mezey's claim that I fear that males will increasingly 'present as women' to access women's spaces is incorrect. As I discussed in my article, predatory males don't have to present as women to self-ID into women's spaces-say-so is sufficient. Some transwomen have beards, wear suits, and present in stereotypically masculine ways; some of these transwomen are indistinguishable from predatory men, and women cannot tell the difference. But the point is, even if we could somehow differentiate transwomen from predatory males, under the EA, it would not matter because saying 'I identify as a woman" is sufficient to gain access into women's spaces.

We are a society that does not operate on trust and self-ID, which is why obvious adults have to show government ID to buy a beer, differentially abled persons have to procure and display a permit to utilize parking spaces set aside for them, and, when access relates to concerns about safety, we employ onerous requirements for proof of who we say we are (e.g., for air travel, for driving licenses). I remain mystified that in this society my critics think allowing any male to self-ID into female spaces is not only acceptable policy, but that it is transphobic to raise concerns about it. To not think that predatory, voyeuristic males will use self-ID to prey upon women and girls is to disregard females because of course they will; they already have. And, as I have noted, self-ID would also undermine the safety of transwomen. 
Second, I dispute Mezey's claim I did not provide sufficient evidence of harm (a discussion that was extended with more examples in the online supplemental information). I presented evidence that gender self-ID has caused physical (sexual assault) and psychological (felt insecurity) harm to females, including violations sufficient to stimulate reversal of gender self-ID policies. However, I must ask, what constitutes sufficient evidence of harm? Male predatory violence against women is well-established; indeed, that is a primary rationale for the sex separation of spaces. What proportion of incarcerated females need say that it would undermine their psychological well-being, including felt security, to have to share a prison cell with a male? How many females need be sexually harassed or assaulted by males in prison for the harm to be sufficient? How many women need express that they want a femaleonly rape-crises shelter in order for at least some to be deemed justifiably sexseparated? How many predatory males need use self-ID to prey on women and girls in formerly sex-separated spaces for this to be considered too great a cost, given alternatives (such as gendered spaces)? Once again, quoting Kathleen Stock (2018), I object to letting females "be the automatic collateral in sweeping social changes such as those proposed".

Mezey states that "[t]here are ample data from jurisdictions with anti-discrimination laws that cast doubt on [my] assertions [read: concerns].' However, Mezey did not cite a single peer-reviewed study in support of this 'ample data' claim because robust scientific evidence does not exist. $\underline{2}$ This follows from the persistent failure to consider the policy impact on females. Government-funded studies have assessed difficulties that transwomen experience in sex-separated spaces, for example, and how this affects their safety and psychological well-being. Yet, no studies have been conducted to examine how women in prisons and shelters might be affected by gender self-ID. These studies are needed because the voices of these women are rarely heard. These women - who are disproportionately poor and minority and who have experience high rates of male sexual violence-matter.

Additionally, I object to Mezey's putting the burden of proof on females to prove that eliminating their sex-based provisions will cause sufficient harm. Insofar as provisions are set aside for a protected group (females) to exclude another group (males), the burden of proof appropriately lies with those seeking exceptions to demonstrate that said exceptions do not increase harm. Instead, Mezey appears to be claiming that women should have to prove, in advance, the harms that may be caused by gender selfID. This is inequitable and illogical, in my view. 
Finally, to Mezey's worry that my discussing the fact that some males will use gender self-ID to prey on females may 'perpetuate discrimination against transgender people', I can only say that need not follow from recognition of facts about male predation (see my discussion of this point: Burt 2020, p.392). Given that concerns about male predation are the primary justification for including transwomen in females' protected spaces, we agree that male predators pose a threat to safety. We disagree that only transwomen can raise concerns about male predatory behavior.

\section{Irrelevant and/or Incorrect}

Mezey criticizes my article for 'ignor[ing] current legal theory and practice that sex discrimination encompasses gender identity discrimination in federal law'. This critique is vague and, in my view, misguided. This is not settled theory or case law. The recent Bostock ruling (590 US_ [2020])_that an employer cannot fire a person simply for being homosexual or transgender-which followed my article, was widely publicized precisely because of the legal uncertainty around these issues. Crucially, the ruling was explicitly narrow. Writing for the majority, Justice Gorsuch emphasized that the ruling did not address provisions where sex distinctions are allowed (as in Title IX). $\underline{3}$ These sex-based provisions are the focus of my critique of the EA.

Mezey also interprets me as holding the belief that females' "oppression is greater" than transwomen's oppression. This is not my argument. I noted that the incidents of harassment and violence against females are much more numerous than those directed against transwomen, but I acknowledged that this is a function of females' outnumbering transwomen by $\sim 100$-fold. Getting mired in an adjudication about which group is "more oppressed" is a futile distraction. Even if transwomen were "more oppressed" than females, it would remain unnecessary-and therefore morally objectionable-to sacrifice the safety of females in order to protect transwomen when alternatives exist that protect both groups. I outlined ways to extend such protections recognizing that both groups are vulnerable and should be protected. $\underline{4}$ These proposals have been largely ignored by my critics.

Ignoring my explicitly deemphasizing bathrooms on my list of concerns (see Burt 2020, footnote 46), Mezey claims I argued for 'access to bathrooms and other sex-segregated places to remain segregated by biological sex.' I proposed having both sex-separated and gendered (or unisex) bathrooms in workplaces and schools. Pivoting and briefly addressing my proposals on gendered spaces, Mezey objects on the basis that protected gendered spaces would 'force transgender individuals to be singled out'. 
First, this does not necessarily follow, as gendered or unisex spaces would be open to anyone. Second, as I discussed, this potential pain of exclusion is counterbalanced by the harm both psychological (loss of felt security and privacy) and physical (violence) from gender self-ID. In the end, given the reality of male sexual violence, I argue it is both ill-advised and morally indefensible to reject a compromise policy prioritizing safety at a cost to inclusivity in favor of a self-ID policy prioritizing inclusivity at a cost of safety.

\section{Sex Denialism}

Professor Upadhyay's (2021) response contains a rich description of the diversity of gender across cultures and contexts. Their critique is rooted in their claim that my article 'espouses transphobic discourses [that] invariably reproduce colonial and white supremacist frameworks of patriarchy and gender violence.' Deeming my approach 'transphobic' and 'cisnormative' 'white feminism', they argue I endorse a heteropatriarchal, racist, colonial view of gender as a binary. I do not. Nowhere have I suggested that gender is a binary. In fact, across several pages in my article (pp. 379384), I make the opposite argument-that gender is a social construction imposed on male and female bodies that should be challenged. In my reading, there is much upon which Upadhyay and I agree: traditional notions of 'womanhood' and 'manhood' are artificial, restrictive, and perpetuate racist and heterosexist ideas that reinforce power structures and there is no right way to be a woman or a man.

Our disagreement is rooted in divergent views about the material reality of sex and the distinction between sex and gender (a topic discussed at length in my article, which was ignored). I believe sexual dimorphism is real and sex matters in some contexts; they disagree. In Upadhyay's account, sex is replaced with socially constructed gender, and the reality of sexual dimorphism is transmuted into a belief in sexual dimorphism, which serves to perpetuate 'cis-white' heteropatriarchy. We agree that hegemonic ideals of 'womanhood', which I explicitly reject, perpetuate inequalities. However, one can-and I do-reject hegemonic norms of femininity and masculinity as defining of 'womanhood' and 'manhood' without denying the material reality of sex and, by implication, the existence of sexism (see Jones 2020). Stripped of all its gendered trappings, male-female differences and females' reproductive burden remain.

Upadhyay charges me with hypocrisy for expressing concerns for how a policy of gender self-ID would affect incarcerated females because incarcerated women are disproportionately racial/ethnic minorities. I do not follow their logic. Recognizing that disadvantaged, minority females are overrepresented in sex-separated spaces, such as 
prisons and shelters, and that, therefore, minority females will be made disproportionately vulnerable to predatory males by gender self-ID policies is not hypocritical, in my view.

Finally, Upadhyay notes they "hopes that in the future, cis-white feminists reflect on their own colonial epistemological frameworks before they analyze trans peoples and issues and reinforcing [sic] transphobia”. Why Upadhyay deems it appropriate to label me 'cis' is unclear, but it is clear that Upadhyay is suggesting that the replacement of sex with gender identity under the law is a 'trans issue' about 'trans people'. Manifestly, it is about sex and gender; however, since Upadhyay has dismissed the reality of sex as something socially constructed from gender, sex-based rights don't exist. Therefore, there is no conflict of rights between sex and gender identity. This is a matter about which we will have to agree to disagree. However, that self-ID undermines the safety of women (however defined) is a topic I hope we can agree is pressing and deserves more discussion.

\section{Spectral Sex, Identity Validation, and Unrealistic Solutions}

In her response, Sherrick interprets my objection to the Equality Act's form as due to an 'expressed concern that in allowing gender to supersede sex, the Equality Act will endanger ciswomen'. She avers that I argued 'only ciswomen should be allowed to enter [women's] spaces.' $\underline{5}$ Then, emphasizing trans people's high 'victimization and suicide rates', Sherrick argues that gender should supersede sex 'to ensure trans people are protected and that their identities are validated".

\section{Correcting the Record}

As I explained in my article, my concern is not merely with the safety of 'ciswomen' (incidentally a term I do not use in my article.) As I have noted, protected spaces cannot exist without gatekeeping. Unchallengeable gender self-ID policies allow male predators to opt in and thereby undermine the safety of everyone in those spaces (females and transwomen). If predation weren't sexed, this situation would be different; however, predation is sexed. Relevant facts Sherrick and others continue to neglect include that males account for $>90 \%$ of sexual assaults and have, as a group, significantly greater size and strength, which allows them to overpower most females if they so choose. Females, as a group, are physically vulnerable to males, which is a primary rationale for sex separated spaces and provisions.

Sherrick ignores my policy suggestions to protect transwomen, including gendered spaces. Notably, I did not argue that all spaces should remain sex separated; rather, I 
proposed the coexistence of gendered and sex-separated spaces with the specification that for some provisions where sex can be salient (e.g., rape crisis or domestic violence shelters), at least one should be female only. Females have unique needs and experiences like transwomen, and both would benefit from provisions that are set aside for them.

\section{Still Two Sexes}

Arguing that the 'science behind gender and sex' is 'neither simple nor binary', Sherrick objects to my recognizing that humans are a sexually dimorphic species. In support of her claims, she cites a widely promulgated (and panned) article by a freelance journalist (Ainsworth 2015), which depicts discrete differences in sexual development as existing on a continuum. As I discussed in my article, sex is not a continuum. People with DSD conditions are sexed. The spectral view of sex implies that people with DSD conditions are 'less female' or 'less male', an implication that is invariably neglected.

For example, on this spectral view, a female with an imperforate hymen (a common form of vaginal atresia caused by the failure of the hymen to open during development which causes vaginal obstruction) - a condition that often is not identified until menarche and is frequently successfully treated with surgical incision, would be considered 'less female' than females without this condition. I object (so too do biologists, see Wright and Hilton [2020] and people with DSD conditions, see Graham [2019]).

Sherrick also cites Anne Fausto-Sterling's (1993) work 'The Five Sexes' as evidence against the sex binary. However, Fausto-Sterling has noted that this work was 'tonguein-check' and not to be taken literally. There is no third sex (much less a fourth or fifth one).

Crucially, my article is not about people with DSD/intersex conditions. Whether or how to conceive of sex with regard to DSD conditions is orthogonal to concerns about transgender issues. People with truly intersex conditions make up a tiny $(<.01 \%)$ proportion of the transgender population like the general population. Whether or not sex is properly conceived as binary (I believe it is) or more of a spectrum given variations in sexual development is irrelevant for the positioning of trans people in society and under the law. Most trans people do not have DSD/intersex conditions. 


\section{Safety First, Identity Validation (Maybe) Later}

Sherrick claims I 'invalidate trans identities' when I point out the so-called 'Wrong Body Model' (i.e., that a person might be a female trapped in a male body) is scientifically unsubstantiated. $\underline{6}$ The idea that objecting to the 'Wrong Body Model' is invalidating or transphobic is belied by the fact that prominent trans scholar activists concur. Bettcher (2013), and others, conceive of this model as 'naturalizing sex and gender in a troubling way,' even as 'frightening' (p.234). Arguably, sex denialism invalidates trans identities because without sex, transgender (as sex-gender mismatch) does not exist. Transwomen are by definition not (biological) females, which is why females cannot be transwomen. Many, perhaps most, trans people acknowledge the reality of sexual dimorphism (see Hayton 2018).

Throughout Sherrick prioritizes the validation of trans people's identities in the crafting of public policies. As I explained in the paper, I disagree. Here the issue is how to balance protections and rights for two groups: females and transwomen. Separate female spaces exist for reasons I discuss in the paper, including but not limited to physical safety from males. Given that my critics are not arguing for unisex spaces, that separate female provisions are necessary and/or justified appears accepted. The crucial question thus emanating is: What is the justification for allowing any male to self-ID into female spaces rather than creating new gender/neutral spaces alongside sex-separated ones. Echoing Mezey before her, the answer is: identity validation.

In their view, women (however defined) should allow any male to self-ID into their (formerly) protected spaces on a say-so to validate the identities of transwomen. The fact that males constitute $>93 \%$ female rapists is apparently of no consequence because, as Sherrick argues, some females rape too. That female-female sexual assault occurs at a rate $>20$-fold lower than that of male-female sexual assault is also evidently of no concern. I don't pretend to understand why (and she doesn't explain).

There is no doubt that many transwomen suffer. But many people suffer, and social policy should be crafted in a manner that ameliorates suffering while reducing harm. The Equality Act fails in this regard. A solution that would require a female with PTSD from male sexual assault (and evidence suggests that 30\% of females suffer from PTSD more than 9 months after sexual assault) to share a room in a women's shelter with a bepenised male against her wishes (and this has already happened) is dismissive of her experiences; it invalidates her pain, felt security, and well-being or at least dismisses her lesser import. There is a term for subordinating female needs, well-being, pain, and accommodations, and the term is not 'feminist' or 'equality'. 
It bears repeating that access to women's provisions is not the solution to the problems that transwomen face. Jenness et al. (2019) documented the appallingly high rates of sexual assault against transwomen in prison; yet, when asked if they would choose to be housed in the women's estate if given the option, more than $60 \%$ said they would opt to remain in the men's prison.

\section{Unrealistic Solutions}

Which brings me to Sherrick's 'solutions', which include laudable policy suggestions that I endorse. As solutions to the immediate problem of predatory males, however, they fall well short of potentially efficacious. One solution involves limiting access to women's spaces to people without histories of sexual assault. However, given that more than $90 \%$ of sexual assaults are not reported, the majority of hidden offenders would be unrestricted? Women's shelters spaces are already woefully overburdened and underfunded. Another involves 'training police officers how to intervene and deescalate sexual violence situations'; I am not sure how this is supposed to work. To my knowledge few to zero sexual assaults occur in the presence of police officers who could intervene.

The reason these solutions fail is quite simple; the goal of balancing "validating trans identities" with "keeping women's spaces safe" is inequitable. I'm unconvinced that public policies should be in the business of promoting identity validation, but if they are, validation should be secondary to physical and psychological safety.

\section{Conclusion}

My article addressed sensitive topics without perfect solutions, requiring compromise. I remain resolute that feminist criminologists have a responsibility to consider how sweeping legislation that would prioritize unchallengeable gender self-ID over biological sex would affect females. This does not imply a prioritization of females or a lack of concern, much less hatred, for transgender people.

\section{References}

Ainsworth, C. (2015). Sex redefined. Nature News, 518(7539), 288.

Bettcher, T. M. (2013). Trans women and the meaning of 'woman'. In N. Power, R. Halwani, \& A. Soble (Eds.), The philosophy of sex: Contemporary readings (pp. 233250). Rowman \& Littlefield. 
Burt, C. H. (2020). Scrutinizing the US Equality Act 2019: A feminist examination of definitional changes and sociolegal ramifications. Feminist Criminology, 15(4), 363-409. Fausto-Sterling, A. (1993). The five sexes: Why male and female are not enough. The Sciences, 33, 20-24.

Graham, C. (2019, September 12). An open letter to Prof. Alice Roberts on the subject of DSDs and kindness. [Weblog post] Retrieved from: https://mrkhvoice.com/index.php/2019/09/12/an-open-letter-to-prof-alice-robertson-the-subject-of-dsds-and-kindness/

Hayton, D. (2018, March 30). A plea to trans activists: We can protect trans rights without denying biology. Quillette. Retrieved from:

https://quillette.com/2018/03/30/plea-trans-activists-can-protect-trans-rights-withoutdenying-biology/

Jenness, V., Sexton, L., \& Sumner, J. (2019). Sexual victimization against transgender women in prison: Consent and coercion in context. Criminology, 57(4), 603-631.

Jones, J.C. (2020). Unreasonable ideas: A reply to Alison Phipps. Weblog post: https://janeclarejones.com /2020/01/15/unreasonable-ideas-a-reply-to-alison-phipps/

Mezey, S. (2021). In favor of the 2019 Equality Act: A Comment on Burt. Feminist Criminology.

Sherrick, A. (2021). Gender Identity and Trans Equality: Comment on Burt 2020. Feminist Criminology, 15570851211006471.

Upadhyay, N. (2021). Coloniality Of White Feminism and Its Transphobia: A Comment on Burt. Feminist Criminology

Wright, C., \& Hilton, E. (2020, February). The dangerous denial of sex. The Wall Street Journal. https://www.wsj.com/articles/the-dangerous-denial-of-sex-11581638089

\section{Acknowledgments}

I am, as always, grateful to Kara Hannula for her extensive feedback and support. I appreciate the feedback from Molly Gardner, Kathleen Stock, and editors whose comments and suggestions guided revisions. I extend thanks to the editors for their courage in publishing my article and for the opportunity to respond. I appreciate all 
those who engaged with the substance of my article with logic and reason rather than misrepresentation or name-calling, whether or not they agree.

\section{Author Bio}

Callie Burt is an associate professor in the Andrew Young School of Policy Studies at Georgia State University. Much of her research focuses on the developmental effects of social inequalities, especially the effects of social risk and protective factors in adolescence, from a biopsychosocial perspective. She has a longstanding interest in sex differences and how these differences are shaped by gender as a social force. More information on her background and her work can be found at www.callieburt.org.

\section{Footnotes}

1. The imperfect, albeit useful, analogy would be a law defining age by selfdeclaration where the statement "I am 21 years old" would make one 21 years old under the law and thus bestow to said person all the rights of 21 -ear-olds, such as eligibility to purchase alcohol. This represents not a blurring but a legal redefinition of age into something else. $\bullet$

2. Although Mezey's initial claim about 'ample evidence' was made without citations, later in the paper three citations were added to same claim. All were nonempirical, non-scholarly pieces by or quoting organizations with particular political aims (namely, treating gender self-ID as sex), including a CNN article that did not include the terms 'homicide' or 'violence' and an HRC report consisting primarily of anecdotal 'stories' $\subseteq$

3. The Court did not extend its holding to other statutes, such as Title IX, or to sex distinctions allowed in Title VII, noting, for example "we do not purport to address bathrooms, locker rooms, or anything else of the kind."

4. For example, I noted: "Both females and trans people should be protected from mistreatment and discrimination. How we do this in a manner that does not elevate one group's disadvantages or challenges as more important or worthy of addressing than other is complicated" (Burt 2020, p.389).

5. Sherrick states in footnote 1 that my "use of 'female spaces' excludes GNCT individuals". It does not; 'female spaces' exclude males; GNCT females are included.

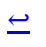


6. My quote, in context, is as follows: "The [gender-as-innate-sex] account is incoherent both because it does not define what "gender identity" is and because explaining how one might have a gender identity-sex mismatch requires a biologically implausible sexed mind-body dualism. Equally important, the idea that "gender identity is an innate, fixed property of human beings that is independent of biological sex-that a person might be a 'a female trapped in a male body' -is not supported by scientific evidence". If a brain is in a male body, it is a male brain (and vice versa)." (Burt 2020, pp.386-7). 